\title{
The role of robotic surgery for endometriosis
}

\author{
Jun-Hyeok Kang, Tae-Joong Kim \\ Department of Obstetrics and Gynecology, Samsung Medical Center, Sungkyunkwan University School of Medicine, Seoul, Korea
}

\begin{abstract}
Endometriosis is a chronic gynecologic disorder characterized by chronic pelvic pain and infertility that affects approximately $11 \%$ of reproductive-aged women. Medical or surgical treatment is essential to manage symptoms and reduce recurrence. When surgical treatment is needed, laparoscopy is considered the gold standard treatment. However, the severity of the disease varies from simple endometrioma to bowel and urinary tract endometriosis, which require radical surgery. With severe endometriosis, even experienced surgeons often need to use laparotomy because of the technical limitations of laparoscopy. Robotic surgery (RS) can be an alternative treatment option because of the advanced visualization, wristed instruments, and ergonomic positioning that it offers to the surgeon. We reviewed previous studies to evaluate the role of RS for endometriosis. Compared with conventional laparoscopy, RS shows similar surgical outcomes, including blood loss and perioperative complications, but it is generally a more time-consuming procedure. RS has no added value for the treatment of early stage endometriosis. However, it does seem to have considerable advantages in complex endometriosis surgery, such as that for advanced stage, bowel, and urinary tract endometriosis, although that has not been shown statistically due to a lack of study. RS can also help prevent conversion to laparotomy and reduce the training period required for inexperienced surgeons. We cannot yet define the definitive role of RS in endometriosis due to its short history, but we note its value for complex surgery. Therefore, RS should be considered in selected patients.
\end{abstract}

Key Words: Endometriosis; Deep infiltrating endometriosis; Robotic surgical procedures; Laparoscopy

\section{INTRODUCTION}

Endometriosis is a common gynecologic disorder defined as the presence of endometrial glands and stroma outside the uterine cavity, with an estimated incidence of $11 \%$ in the population [1]. It commonly affects the pelvic organs and can also be found outside the pelvic cavity. Although patients with endometriosis can be asymptomatic, 35-50\% of them suffer from severe pelvic pain, infertility, and other symptoms that depend on the location of the lesion [2,3].
Endometriosis can also decrease quality of life (QOL) and increase overall healthcare costs [4].

Surgical resection of all visible lesions using laparoscopy has been considered the gold standard for treating endometriosis when medical treatment fails $[5,6]$. A complete resection of endometriosis is important to prevent disease recurrence, relieve pain, and improve fertility. However, in complex cases of endometriosis, e.g., stage III or IV according to the revised American Society for Reproductive Medicine classification, achieving that goal through laparoscopy

- Received: June 28, 2020 •Revised: September 13, 2020 •Accepted: September 14, 2020

- Correspondening author: Tae-Joong Kim

Department of Obstetrics and Gynecology, Samsung Medical Center, Sungkyunkwan University School of Medicine, 81 Irwon-ro, Gangnam-gu, Seoul 06351, Korea

E-mail: tj28.kim@gmail.com

This is an Open Access article distributed under the terms of the Creative Commons Attribution Non-Commercial License (http://creativecommons.org/ licenses/by-nc/4.0) which permits unrestricted non-commercial use, distribution, and reproduction in any medium, provided the original work is properly cited. 


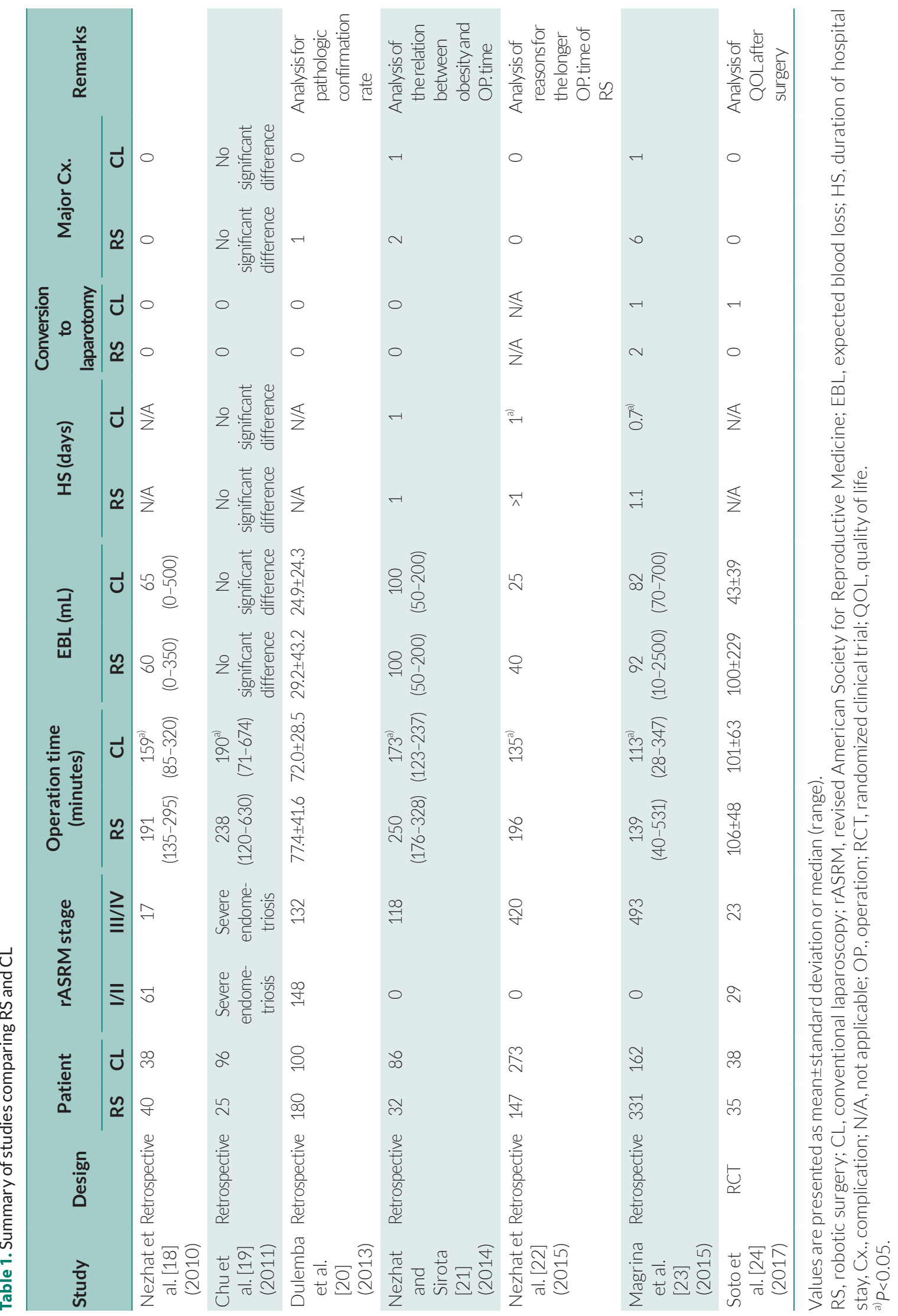


gical field and controls the robotic instruments and camera via finger graspers and pedals. The operator can thus feel comfortable and experience less fatigue despite long operative times [11,15]. The near-infrared fluorescence-indocyanine green (NIRF-ICG, firefly) technique of robot surgery can also improve the detection of endometriosis lesions invisible to the naked eye in white light (WL) illumination $[16,17]$. All of these advantages help robot surgery ensure a complete resection of endometriosis.

Our literature review found eight studies comparing RS with $\mathrm{CL}$ for the treatment of endometriosis. Among them, six were retrospective comparative studies, one was a randomized clinical study, and one was a meta-analysis. The year of publication, study design, and results of all the studies except the meta-analysis are shown in Table 1.

The first study to compare RS and CL for endometriosis treatment was conducted in 2010 by Nezhat et al. [18]. They found no significant differences in perioperative outcomes between the two groups except in operative time (mean [range]; RS, 191 [135-295] minutes vs. CL, 159 [85320] minutes; $P=0.045)$. However, most patients in that study cohort had stage I or II disease; only $22 \%$ (27/78) of patients had advanced stage endometriosis. They concluded that RS is feasible and safe for the treatment of endometriosis but that the superiority of RS for early stage disease is unclear. Since then, several studies have evaluated the role of RS in advanced stage endometriosis. Chu and colleagues [19] retrospectively compared RS ( $n=25)$ and $C L$ $(n=96)$ for the treatment of severe endometriosis. They also found comparable surgical outcomes between the groups and that RS required a longer mean operative time than CL (238 vs. 190 minutes, $P=0.05$ ). According to a study of 280 patients with endometriosis (RS, 180 vs. CL, 100) performed by Dulemba et al. [20], RS had similar surgical outcomes including mean operation time (RS, 77.4 minutes vs. $C L, 72.3$ minutes; $P=0.23$ ), in contrast to the previous study results regarding operation time. Interestingly, their group compared the rate of biopsy-confirmed endometriosis patients between the two groups and found that the RS group had a higher confirmation rate than the $C L$ group (RS, 80\% vs. CL, 56.8\%; $P<0.001$ ) due to its better visualization. They revealed that robot surgery can improve the diagnosis and excision of implanted tissue over that available with $\mathrm{CL}$, with comparable perioperative out- comes. In a study of patients with advanced stage endometriosis ( $n=118$ ) by Nezhat and Sirota [21], RS was a more time-consuming procedure than $\mathrm{CL}$, and other surgical outcomes, such as complications and conversion rate, were comparable between the two groups. In particular, they evaluated the effect of obesity on surgery. After obesity stratification, they found no significant differences in operative time between RS and CL among normal weight and overweight patients. In obese patients, however, the operative time for RS was longer than that for CL (median [range]; 282.5 [224-342] vs. 174 [130-270] minutes; $P<0.05$ ). They argued that RS is a feasible and safe procedure for the treatment of endometriosis but that it should be used only for complex operations that require fine dissection. They revealed that the longer operation time of RS compared with $C L$ is related to obesity.

Two large retrospective studies have been done. A study by Nezhat et al. [22] of 420 patients who underwent surgery for advanced stage endometriosis (RS, 147 vs. CL, 273) found no differences in surgical outcomes between the two groups. However, the RS group had a longer mean operative time (196 vs. 135 minutes, $P<0.001$ ) and longer hospital stay $(P<0.001)$. Their findings were consistent with previous studies in terms of the increase in overall operative time with RS. They also analyzed the factors that contribute to the longer operation time and found that docking and undocking time, the size of endometrioma, the fact that $\mathrm{a} \mathrm{CO}_{2}$ laser is not available in the RS setting, the presence of upper abdomen disease, and the lack of tactile sense with RS contributed to the increased operative time. In another large study of 493 patients with advanced stage endometriosis (RS, 331 vs. CL, 162) [23], the only difference between two groups in surgical outcomes was operation time. Those authors explained that the longer operation time with RS stemmed from the higher number of additional procedures and more radical operations performed in the robot group.

The only randomized clinical trial (RCT) comparing RS vs. CL for advanced endometriosis was conducted with 73 patients (RS, 35 and CL, 38) by Soto et al. [24] in 2017. They found no statistically significant differences between RS and $C L$ in surgical outcomes, including operative time (mean \pm standard deviation; $106 \pm 48.4$ and $101.6 \pm 63.2$ minutes; $P=0.71$ ). That study also compared $Q \mathrm{QL}$ scores from 
baseline, 6 weeks, and 6 months after surgery and found no significant differences between the two groups. Both groups reported significant improvements in QOL at both postoperative times compared with their preoperative baseline.

One previous meta-analysis by Chen et al. [25] evaluated the safety and efficacy of RS vs. CL for the treatment of advanced stage endometriosis. According to that analysis, RS has a significantly longer operation time than $C L(P<0.01)$. However, they found no difference between RS and CL in the duration of hospital stay, complication rate, or blood loss. They concluded that RS is a safe and efficient alternative to $\mathrm{CL}$ for the treatment of advanced stage endometriosis, although RS is time-consuming and the overall cost remains high. The benefits of RS for the treatment of advanced endometriosis thus remain uncertain.

\section{ROBOTIC SINGLE-SITE SURGERY TO TREAT ENDOMETRIOSIS}

With an increase in the demand for minimally invasive surgery (MIS), robotic single site (RSS) surgery has developed since 2013 as an alternative to RS in various surgical fields. RSS surgery requires only a small incision of $3 \mathrm{~cm}$ to place a single multichannel port, whereas RS requires the placement of at least four trocars. Therefore, RSS is less invasive, causes less pain, and offers better cosmesis after surgery than RS $[26,27]$. Given that most women who suffer from endometriosis are young and susceptible to scarring, the cosmesis of the surgical scar is an important issue $[28,29]$. Single-port laparoscopy (SPL) is more difficult than $\mathrm{CL}$ because limitations in space and movement lead to conflicts among instruments. RSS surgery overcomes those problems with crossed and flexible instruments. We thus assume that surgeons can remove endometriosis lesions more easily using RSS surgery than SPL and that RSS can achieve cosmetic goals better than RS surgery.

In our literature review, we found some case reports about the excision of endometriosis using RSS surgery and one retrospective study comparing the outcomes of RSS surgery and SPL for endometriosis. The first case report of one patient using RSS surgery for endometriosis was written by Guan et al. [16] in 2015. They successfully resected advanced endometriosis using RSS surgery and an ICG in- jection. Jayakumaran and colleagues [17] reported their experience performing RSS surgery for endometriosis in seven patients. All the visible endometriosis lesions in those seven patients were successfully resected without any complication or the conversion to another surgical method. Interestingly, their group compared the number of endometriosis lesions found using different endoscopic visualization techniques: laparoscopic WL illumination, robotic WL illumination, and NIRF-ICG imaging. The NIRF-ICG imaging detected more endometriosis lesions than the other visualization methods. They argued that RSS surgery combined with this advanced visualization technique facilitated more complete endometriosis lesion detection and excision. A retrospective study in 2018 compared the surgical outcomes from RSS surgery ( $n=68$ ) with those from SPL ( $n=52$ ) for the treatment of advanced-stage endometriosis [30]. RSS surgery showed comparable surgical outcomes, including duration of hospital stay and perioperative complications, with SPL except for mean operation time (RSS surgery, 107.8 minutes vs. SPL, 76.9 minutes; $P=0.001$ ) and estimated blood loss (106.6 vs. $57.1 \mathrm{~mL}, P=0.001$ ). That study suggested that RSS surgery is feasible, safe, and effective for the treatment of advanced stage endometriosis.

Another novel single port robotic platform, the da Vinci ${ }^{\circledR}$ SP Surgical System (Intuitive Surgical, Sunnyvale, CA, USA) uses a single robotic arm that contains an articulating camera and instruments docked from a single laparoscopic trocar. Initial reports on this system were published in other fields, such as urologic surgery, and they suggested that this new technology is a safe and feasible surgical option compared with prior procedures [31,32]. However, no report has yet been published about the use of this platform for endometriosis.

\section{RS FOR DIE AND EXTRAGENITAL ENDO- METRIOSIS}

DIE is diagnosed when endometriosis occurs more than $5 \mathrm{~mm}$ deep into the peritoneum. Approximately $40 \%$ of patients with endometriosis have DIE [33]. It is usually found in the rectovaginal space (70\%), but it also occurs in the bowel (12\%), urinary tract (9\%), and pelvic peritoneum $[34,35]$. The infiltrative nature of DIE can cause dense adhesions and fibrosis and distort pelvic structures, including 
genital organs, the bowel, and urinary tract. This can cause severe pelvic pain. Because DIE lesions are not easily treated medically, complete radical excision and the restoration of normal anatomy to reduce pain and the recurrence rate are the most important points in managing such patients. To achieve that goal, particular skills, such as dissecting the deep retroperitoneal space, isolating the ureter and the bowel, and suturing technique, are essential. However, those procedures are challenging using CL. Therefore, especially in DIE and extragenital endometriosis, RS can be a strong, attractive option.

\section{DIE in bowel}

Bowel involvement with deep endometriotic nodules is reported $8-12 \%$ of endometriosis cases (Fig. 2). Of them, the recto-sigmoid junction (65\%) is the most common site, followed by the rectum (15-20\%). Bowel-involved endometriosis can cause cyclic bowel symptoms, dyschezia, bloating, and rectal bleeding [36-38]. The surgical treatment for bowel endometriosis depends on the depth of bowel wall invasion and ranges from shaving to segmental resection [39]. Although the current surgical standard is based on laparoscopic surgery, some bowel surgery procedures are difficult to perform using laparoscopy due to the possibility of major complications such as bowel perforation and leakage. Therefore, many surgeons abandon laparoscopic surgery when they have to do bowel surgery and convert to laparotomy. Without a doubt, RS offers advan- tages over laparoscopy in complex bowel operations.

Since the introduction of robot systems, many attempts have been made to evaluate the feasibility of RS in treating advanced colorectal endometriosis with DIE. Most studies found during our literature search were case reports (Table 2). Nezhat et al. [40] reported the first two cases of successful RS management for bowel endometriosis (segmental bowel resection and disc excision of the anterior rectal wall) without any complications. Since then, many studies have reported surgical outcomes of RS for bowel endometriosis. According to a study by Lim et al. [41] comparing the surgical outcomes of RS ( $n=8)$ and laparotomy $(n=10)$ for low anterior resection to treat endometriosis, RS showed similar surgical outcomes with fewer complications than laparotomy. Although that study included a small number of patients, it was the first to compare laparotomy with RS in the treatment of bowel endometriosis. Ercoli et al. [42] used RS to perform complete excision from 22 patients who had DIE with colorectal involvement (segmental resection, 12 and bowel wall shaving, 10). Only one case had a major postoperative complication (small bowel obstruction), and there was no conversion to laparotomy. They demonstrated that using RS for complete debulking of DIE with colorectal involvement is feasible and safe and can be done without conversion to other surgical methods. Collinet and colleagues [43] reported that their group successfully used $\mathrm{RS}$ in 96 patients who received segmental rectal resection, rectal shaving, and ileocecectomy without any major post-
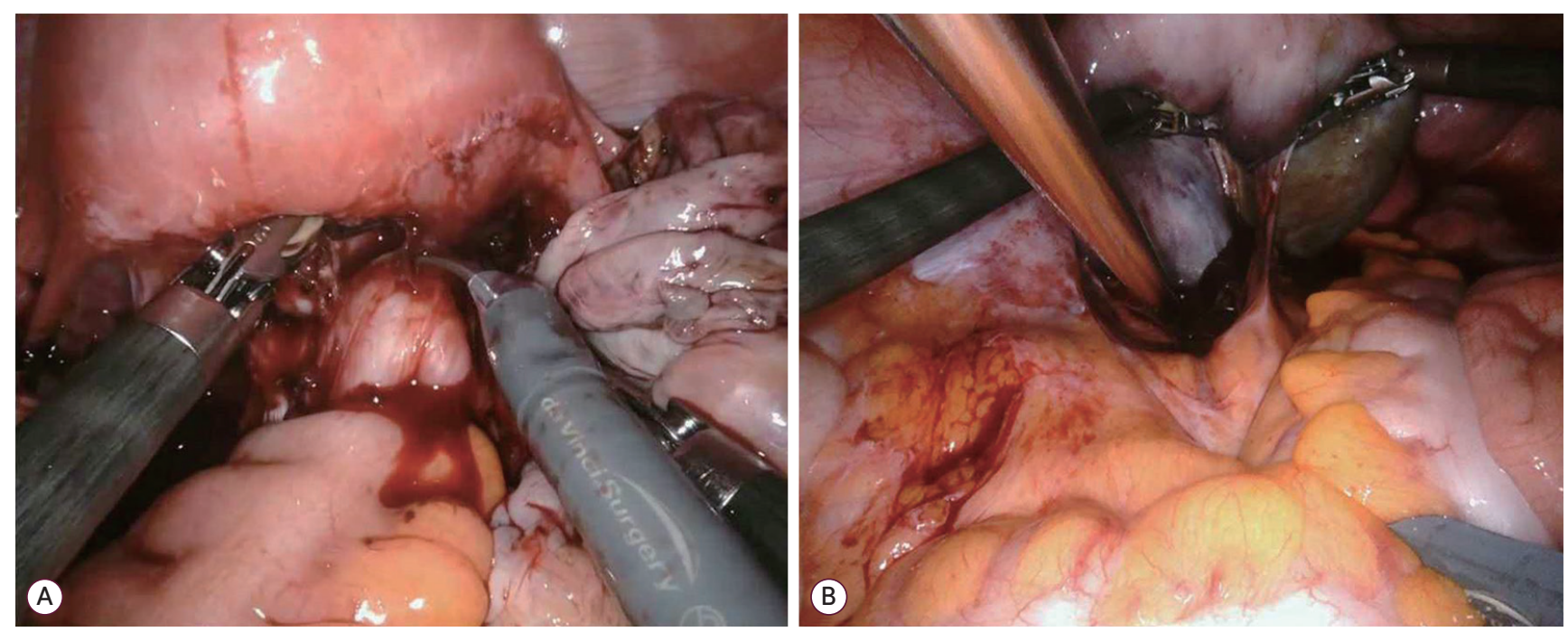

Fig. 2. (A) Rectum involvement. (B) Sigmoid colon involvement. 
Table 2. Summary of studies about robot surgery for DIE with bowel and urinary tract involvement

\begin{tabular}{|c|c|c|c|c|}
\hline Study & Design & Patient & Operation name & Major complication \\
\hline \multicolumn{5}{|l|}{ Colorectal DIE } \\
\hline Nezhat et al. [40] (2011) & Case report & 2 & $\begin{array}{l}\text { Segmental bowel resection }(n=1) \\
\text { Disc excision }(n=1)\end{array}$ & No complications \\
\hline Lim et al. [41] (2011) & $\begin{array}{l}\text { Comparative } \\
\text { Prospective }\end{array}$ & 8 & Low anterior resection $(n=8)$ & No complications \\
\hline Ercoli et al. [42] (2012) & Case series & 22 & $\begin{array}{l}\text { Segmental bowel resection }(n=12) \\
\text { Colorectal wall shaving }(n=10)\end{array}$ & Small bowel obstruction $(n=1)$ \\
\hline $\begin{array}{l}\text { Vitobello et al. [45] } \\
\text { (2013) }\end{array}$ & Case report & 7 & $\begin{array}{l}\text { Segmental bowel resection }(\mathrm{n}=7) \text { : } \\
\text { hybrid technique }(R S+C L)\end{array}$ & Reoperation due to bleeding \\
\hline Neme et al. [44] (2013) & Case report & 10 & Segmental bowel resection $(n=10)$ & No complications \\
\hline Siesto et al. [46] (2014) & Case series & 42 & $\begin{array}{l}\text { Rectal shaving }(n=23) \\
\text { Segmental bowel resection }(n=19)\end{array}$ & $\begin{array}{l}\text { Anastomosis leakage }(n=1) \\
\text { Reoperation due to bleeding }(n=1)\end{array}$ \\
\hline Collinet et al. [43] (2014) & $\begin{array}{l}\text { Case series } \\
\text { Retrospective } \\
\text { Multicenter }\end{array}$ & 97 & $\begin{array}{l}\text { Rectal shaving }(n=68) \\
\text { Segmental rectal resection }(n=24) \\
\text { lleocecectomy }(n=1) \\
\text { Appendectomy }(n=3) \\
\text { Stoma }(n=1)\end{array}$ & $\begin{array}{l}\text { Rectal perforation during rectal } \\
\text { shaving surgery }(n=2)\end{array}$ \\
\hline $\begin{array}{l}\text { Pellegrino et al. [47] } \\
\text { (2015) }\end{array}$ & $\begin{array}{l}\text { Case series } \\
\text { Prospective }\end{array}$ & 25 & Rectal shaving $(n=25)$ & $\begin{array}{l}\text { Rectal perforation during rectal } \\
\text { shaving surgery }(n=1)\end{array}$ \\
\hline Abo et al. [48] (2017) & Case series & 35 & $\begin{array}{l}\text { Rectal shaving }(n=25) \\
\text { Disc excision }(n=3) \\
\text { Segmental bowel resection }(n=3)\end{array}$ & No complications \\
\hline Morelli et al. [49] (2016) & Case report & 10 & $\begin{array}{l}\text { Segmental rectal resection }(n=6) \\
\text { Sigmoid-rectal resection }(n=4)\end{array}$ & No complications \\
\hline Graham et al. [50] (2019) & Case series & 57 & $\begin{array}{l}\text { Segmental rectal resection }(n=12) \\
\text { Disc excision or rectal shaving }(n=42)\end{array}$ & Rectovaginal fistula $(\mathrm{n}=1)$ \\
\hline \multicolumn{5}{|l|}{ Urinary tract DIE } \\
\hline Nezhat et al. [40] (2011) & Case report & 3 & $\begin{array}{l}\text { Ureteroneocystostomy }(\mathrm{n}=1) \\
\text { Segmental bladder resection }(\mathrm{n}=1) \\
\text { Ureterolysis }(\mathrm{n}=1)\end{array}$ & No complications \\
\hline $\begin{array}{l}\text { Bot-Robin et al. [53] } \\
\text { (2011) }\end{array}$ & Case report & 4 & Partial bladder resection $(n=4)$ & No complications \\
\hline Frick et al. [54] (2011) & Case report & 2 & Ureteroneocystostomy $(n=2)$ & No complications \\
\hline Brudie et al. [55] (2012) & Case report & 29 & Ureterolysis (n=29) & Ureteral transection $(n=1)$ \\
\hline Collinet et al. [43] (2014) & $\begin{array}{l}\text { Case series } \\
\text { Multicenter }\end{array}$ & 87 & $\begin{array}{l}\text { Ureteroneocystostomy }(n=3) \\
\text { Partial bladder resection }(n=22) \\
\text { Ureterolysis }(n=62)\end{array}$ & $\begin{array}{l}\text { Ureteral fistula }(n=2) \\
\text { Ureter and bladder anastomosis site } \\
\text { leakage }(n=1) \\
\text { Prolonged self catheterization }(n=1)\end{array}$ \\
\hline Siesto et al. [46] (2014) & Case series & 7 & $\begin{array}{l}\text { Bladder resection }(n=5) \\
\text { Ureterolysis }(n=2)\end{array}$ & No complications \\
\hline $\begin{array}{l}\text { le Carpentier et al. [52] } \\
\text { (2016) }\end{array}$ & $\begin{array}{l}\text { Retrospective } \\
\text { Comparative }\end{array}$ & $\begin{array}{l}37 \text { (RS, 15; } \\
\quad \text { CL, 22) }\end{array}$ & Partial bladder resection $(n=37)$ & $\begin{array}{l}\text { Vesicovaginal fistula }(\mathrm{CL}, \mathrm{n}=1) \\
\text { Ureter and bladder anastomosis site } \\
\text { leakage }(\mathrm{RS}, \mathrm{n}=1) \\
\text { Dehiscence of bladder }(\mathrm{CL}, \mathrm{n}=1)\end{array}$ \\
\hline
\end{tabular}


Table 2. Continued

\begin{tabular}{|c|c|c|c|c|}
\hline Study & Design & Patient & Operation name & Major complication \\
\hline Abo et al. [48] (2017) & Case series & 16 & $\begin{array}{l}\text { Partial bladder resection }(n=3) \\
\text { Ureterolysis }(n=11) \\
\text { Ureteroneocystostomy }(n=2)\end{array}$ & Ureteral necrosis and fistula $(n=1)$ \\
\hline Giannini et al. [56] (2018) & Case series & 31 & Ureterolysis (n=31) & $\begin{array}{l}\text { Ureteral fistula }(n=2) \\
\text { Hydronephrosis }(n=1) \\
\text { Ureterovesical reimplantation due to } \\
\text { ureter injury }(n=1)\end{array}$ \\
\hline
\end{tabular}

RS, robotic surgery; CL, conventional laparoscopy; DIE, deep infiltrating endometriosis.

operative complications. Neme et al. [44] reported that they successfully performed bowel resection using RS in 10 patients without any complications or conversion to laparotomy. Symptoms related to endometriosis (dysmenorrhea, dyspareunia, dyschezia, intestinal cramping, diarrhea, and constipation) had disappeared in all women 12 months after surgery. They also suggested that RS bowel resection surgery for the treatment of deep infiltrating bowel endometriosis is feasible, effective, and safe. In addition, Vitobello et al. [45], Siesto et al. [46], Pellegrino et al. [47], and Abo et al. [48] published reports of their successful experiences using RS for bowel endometriosis, including rectal shaving and segmental bowel resection. Most cases were successful and without complication, and the authors all argued for the feasibility of RS.

Morelli et al. [49] reported successful surgical outcomes from bowel resection using RS ( $n=10)$. Unlike previous studies, they used questionnaires to assess autonomic function preservation after surgery, such as urinary function and sexual function. According to their study result, dyspareunia was significantly improved 12 months after surgery. Urinary function and other symptoms showed results similar to those before surgery. They argued that the better visualization and precise control offered by RS can facilitate nerve sparing, such as the hypogastric nerve and sacral splanchnic nerve, which can easily be damaged during bowel surgery. They suggested that RS is a better surgical method for the preservation of urinary and sexual function than laparotomy or laparoscopy. A retrospective analysis of 57 women who underwent RS for colorectal DIE was published in 2019. Among them, 15 patients received a bowel resection and the remaining 42 patients underwent only excision of endometriotic nodules. No intraoperative com- plications or conversion to laparotomy was reported [50].

\section{DIE in the urinary tract}

The urinary tract, including the ureter, bladder, and kidney, is frequently affected by endometriosis, which can cause symptoms such as dysuria, hematuria, urinary frequency, and ureteral obstruction (Fig. 3). The incidence of urinary tract endometriosis is approximately $10 \%$ of endometriosis patients, and the bladder is the most common site [51]. Superficial endometriotic lesions on the bladder and ureter can easily be treated with simple excision or fulguration. However, deep endometriotic lesions, such as an infiltration of the detrusor muscle of the bladder or the muscularis, lamina propria, or lumen of the ureter can require extensive resection and re-anastomosis. In those surgeries, fine dissection to identify the ureter and precise suturing for anastomosis of the resected ureter are the most important techniques, and laparoscopy presents many limitations to performing them. Therefore, we assume that RS is well suited to those types of surgical interventions because of its advantages, which we've already described.

Our literature review returned several case reports about treating urinary tract endometriosis using RS (Table 2). However, no RCT studies have been done. All the previous reports had small sample sizes. A relatively large retrospective multicenter study was conducted by Collinet et al. [43]. Their group performed ureterolysis ( $n=62$ ), ureteroneocystostomy ( $n=3$ ), and partial bladder resections ( $n=22$ ) and reported major complications to the urinary tract in approximately $4 \%$ of patients. A study by le Carpentier et al. [52] compared surgical outcomes between RS and CL for bladder endometriosis. RS showed similar surgical outcomes, including perioperative complications and recur- 

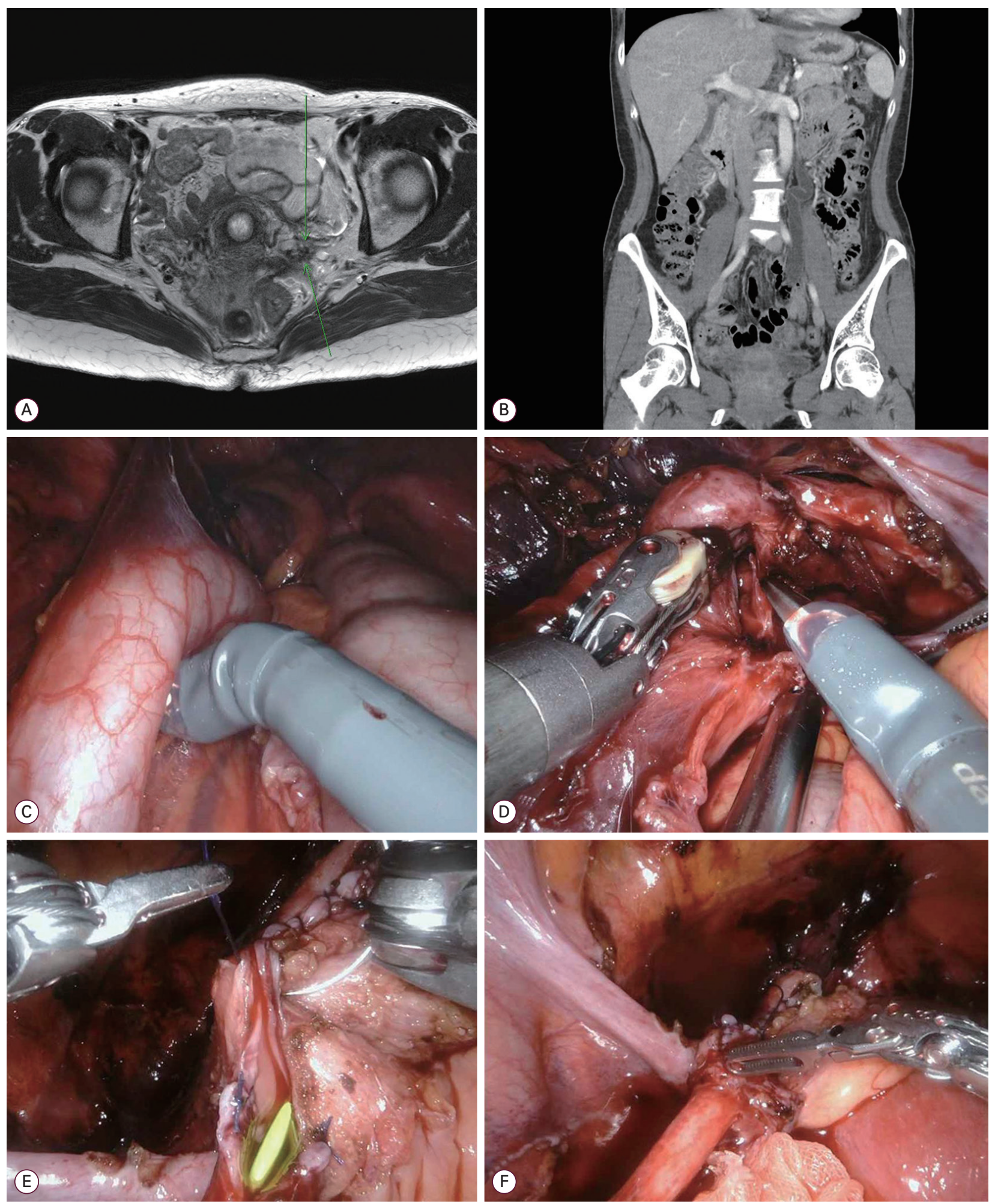

Fig. 3. (A) Deep infiltrating endometriosis (DIE) on the left distal ureter (magnetic resonance imaging [MRI] imaging). (B) Left hydroureter caused by left distal ureter obstruction due to DIE (computed tomography [CT] imaging). (C) Exposed left ureter after dissection of retroperitoneum using robotic surgery. (D) DIE lesion on the left distal ureter. (E) Robotic suturing during ureteroneocystostomy. (F) Successfully performed ureteroneocystostomy. 
rence rate. The conclusion of the other case reports was that RS is safe and feasible for urinary tract endometriosis [40,53-56].

\section{DISCUSSION}

Since the introduction of robot surgery, it has been widely used to treat gynecologic disease. However, in the early days of RS, it was not usually recommended for benign gynecologic disease. According to the American College of Obstetrician and Gynecologists (ACOG) Committee Opinion No. 628 announced in 2015, although RS has comparable surgical outcomes, including complications, length of hospital stay, rate of conversion to laparotomy compared to $\mathrm{CL}$, it requires similar or longer operation times and has higher costs. ACOG thus recommends that operators avoid the use of robot for benign gynecologic disease when it is feasible to use $\mathrm{CL}$ or a vaginal approach. However, such statements are mainly based on data from benign gynecologic conditions other than endometriosis, which can require complex and difficult surgical procedures. In addition, this opinion has now been withdrawn due to technical advances and accumulation of much experience, and the value of RS in benign gynecologic disease is being reevaluated. Therefore, the role of RS for endometriosis needs to be reconsidered.

We reviewed documentation from the past 10 years on robot surgery for endometriosis. Most studies were case reports, retrospective, observational, and non-comparative. Due to the short history of RS, only one RCT has compared surgical outcomes between RS and CL. Therefore, there are some limitations in determining the exact role RS should play in endometriosis treatment. Our review has found no evidence indicating that RS is superior to CL for the treatment of endometriosis, similar to previous studies evaluating the role of RS in benign gynecologic disease. Of seven comparative studies, five studies [18,19,21-23] reported that RS did not show any superiority to CL with respect to surgical outcomes, and they reported that it involves significantly longer operation time regardless of the severity of endometriosis. The one meta-analysis [25] also concluded that RS is a more time-consuming procedure. In contrast, two comparative studies, one retrospective [20] and the one RCT [24], reported that RS has an operation time comparable to that of CL. RS has several time-consuming factors. First is the docking time, which has been traditionally pointed out as time-consuming factor [57]. Second, surgeons cannot be guided by tactile feedback during surgery. The absence of the tactile sense correlates with longer operation times and a higher complication rate because it is difficult to perform a careful dissection and detect firm endometriosis lesions without it [58]. Third, the position of the robotic camera is fixed on the umbilical port and cannot be changed during surgery. The robotic arm also has a limited range of motion. These limitations are not a critical problem for pelvic surgery, but extrapelvic disease could require redocking of the robot for upper abdomen surgery. However, those processes are increasingly being improved through new docking techniques, advanced visualization from the camera to compensate for the tactile sense, and the da Vinci ${ }^{\circledR}$ SP Surgical System, which provides an easier approach to the upper abdomen.

Overall, RS has no statistically proven benefit compared with $\mathrm{CL}$ according to recent studies. Does that mean that clinicians should refrain from this expensive and time-consuming procedure when treating endometriosis? Many experienced laparoscopic surgeons agree that RS can be appropriate, especially in treating severe endometriosis that requires difficult surgical procedures. RS has many advantages over $C L$ in complex surgery, such as precise control, magnified and advanced 3D visualization, ergonomic positioning, and a short learning curve. Moreover, these advantages can reduce operator's fatigue in complex surgery and may enable to do more cases of surgery at the same time compared to $\mathrm{CL}$. The indications for RS in treating endometriosis have not been well established. Therefore, it is important to use in selecting patients suitable for robot surgery.

Our review suggests some conditions that are appropriate for RS. First, patients with severe pelvic adhesions, such as posterior cul-de-sac obliteration, that require fine dissection and the restoration of normal anatomy can be excellent candidates. Most patients with severe endometriosis feel severe pelvic pain. Removing as many lesions as possible and normalizing pelvic anatomy is essential to reduce pain and the recurrence rate in such patients. The technical advantages of robot surgery, as explained above, enable surgeons to more completely detect and resect the disease 
$[17,20]$. Second, patients who need bowel and urinary tract surgery that carries high complication rates and conversion to laparotomy are good candidates for RS [59,60]. Radical surgery, such as segmental bowel resection, low anterior resection, and ureteroneocystostomy, is required in some patients. Traditionally, those radical surgeries required conversion to laparotomy. No comparative study has examined the complication rate and conversion rate of $\mathrm{CL}$, laparotomy, and RS in those cases. Therefore, we cannot draw the conclusion that RS is superior to $\mathrm{CL}$ during radical surgery. However, we can speculate that RS has definite advantages for radical surgery. For example, precise dissection and good visualization facilitate the removal of endometriosis lesions without nerve injury, especially to the inferior hypogastric plexus, which is important for postoperative urinary, sexual, and bowel function [61,62]. Furthermore, a reduction in vessel injury and electrocoagulation during RS contributes to healing at the anastomosis site and reduces the possibility of fistula formation [63]. Finally, surgeons without much experience doing complex surgeries with $\mathrm{CL}$ techniques might find RS easier and more comfortable. It has been reported that the learning curve for RS is generally shorter than that for $\mathrm{CL}[64,65]$. In particular, suturing technique is faster with a robot than in $\mathrm{CL}$ [66]. Of course, that might not be an important issue for experienced surgeons; however, it can be a strong advantage to beginners. Those indications for RS are hypothetical. No statistically proven indications are available because most published studies have been case reports and not RCTs.

MIS is another emerging issue in gynecologic surgery. Prior robot surgery platforms do not qualify as MIS because they require at least four trocars. One disadvantage of RS compared with SPL is cosmesis. The development of a single site platform for robot surgery can overcome the cosmetic shortcomings of both previous robot platforms and CL. RSS surgery, which is similar to SPL, shows surgical outcomes comparable to those of SPL [30]. Furthermore, it has several strengths over SPL when treating endometriosis. For example, the wristed robotic arm and curved trocars of RSS help to maintain triangulation, which is a technical obstacle for SPL. Second, RSS surgery provides a wider range of motion than SPL. Surgeons can do precise dissections and meticulous ovarian suturing in a single-site setting without collisions between surgical instruments. Further- more, the development of the da Vinci ${ }^{\circledR}$ SP system is expected to provide even more range of motion in the robotic arm and an easier approach to the upper abdomen than RSS surgery platforms. However, no study has considered the use of a single-port robotic system for endometriosis because of its short history.

In conclusion, using RS to treat endometriosis is expected to have several technical advantages, but it has no statistically proven benefit over $\mathrm{CL}$ and is associated with a longer operation time and higher cost. Standardized comparative research designs are difficult due to the diversity of extent in endometriosis surgery, which depends on the severity of endometriosis and disease location, e.g., from simple cystectomy of endometrioma to a bowel resection that requires radical surgery. Furthermore, due to the short history of RS, most studies compared laparoscopy performed by highly experienced surgeons with RS performed by surgeons who were relatively inexperienced in robot surgery. RS has no added value for the treatment of early stage endometriosis. However, it seems that RS could have strong advantages for complex endometriosis surgery. It can also help to prevent conversion to laparotomy and reduce the training period for inexperienced surgeons. Most studies about robot surgery for endometriosis have evaluated only perioperative outcomes, such as blood loss, operation time, and complication rate. Considering that most patients who suffer from this disease are young, reproductive-aged women, fertility rates and the preservation of ovarian reserve after surgery are other important problems that no study has investigated. As the proportion of RS increases in the field of MIS, it is expected to play an important role in complex function-preserving surgeries, including endometriosis surgery. To make better decisions about its utility, long-term outcome studies and RCTs should be conducted.

\section{Conflict of interest}

No potential conflict of interest relevant to this article was reported.

\section{References}

1. Zondervan KT, Becker CM, Missmer SA. Endometriosis. N Engl J Med 2020;382:1244-56. 
2. Sensky TE, Liu DT. Endometriosis: associations with menorrhagia, infertility and oral contraceptives. Int J Gynaecol Obstet 1980;17:573-6.

3. Simoens S, Dunselman G, Dirksen C, Hummelshoj L, Bokor A, Brandes I, et al. The burden of endometriosis: costs and quality of life of women with endometriosis and treated in referral centres. Hum Reprod 2012;27:1292-9.

4. Houston DE. Evidence for the risk of pelvic endometriosis by age, race and socioeconomic status. Epidemiol Rev 1984;6:167-91.

5. Kaur KK, Allahbadia G, Singh M. Current role of surgery in endometriosis; indications and progress. Surg Med Open Acc J 2018;1:1-7.

6. Yeung PP Jr, Shwayder J, Pasic RP. Laparoscopic management of endometriosis: comprehensive review of best evidence. J Minim Invasive Gynecol 2009;16:269-81.

7. Jansen FW, Kapiteyn K, Trimbos-Kemper T, Hermans J, Trimbos JB. Complications of laparoscopy: a prospective multicentre observational study. Br J Obstet Gynaecol 1997;104:595-600.

8. Worley MJ, Slomovitz BM, Ramirez PT. Complications of laparoscopy in benign and oncologic gynecological surgery. Rev Obstet Gynecol 2009;2:169-75.

9. Park JY, Kim TJ, Kang HJ, Lee YY, Choi CH, Lee JW, et al. Laparoendoscopic single site (LESS) surgery in benign gynecology: perioperative and late complications of 515 cases. Eur J Obstet Gynecol Reprod Biol 2013;167:215-8.

10. Sinha R, Sanjay M, Rupa B, Kumari S. Robotic surgery in gynecology. J Minim Access Surg 2015;11:50-9.

11. Lawrie TA, Liu H, Lu D, Dowswell T, Song H, Wang L, et al. Robotassisted surgery in gynaecology. Cochrane Database Syst Rev 2019;4:CD011422.

12. Kennedy S, Bergqvist A, Chapron C, D'Hooghe T, Dunselman G, Greb R, et al. ESHRE guideline for the diagnosis and treatment of endometriosis. Hum Reprod 2005;20:2698-704.

13. Vignali M, Bianchi S, Candiani M, Spadaccini G, Oggioni G, Busacca M. Surgical treatment of deep endometriosis and risk of recurrence. J Minim Invasive Gynecol 2005;12:508-13.

14. Marchal F, Rauch P, Vandromme J, Laurent I, Lobontiu A, Ahcel B, et al. Telerobotic-assisted laparoscopic hysterectomy for benign and oncologic pathologies: initial clinical experience with 30 patients. Surg Endosc 2005;19:826-31.

15. Visco AG, Advincula AP. Robotic gynecologic surgery. Obstet Gynecol 2008;112:1369-84.

16. Guan X, Nguyen MT, Walsh TM, Kelly B. Robotic single-site endometriosis resection using firefly technology. J Minim Invasive Gynecol 2016;23:10-1.

17. Jayakumaran J, Pavlovic Z, Fuhrich D, Wiercinski K, Buffington C, Caceres A. Robotic single-site endometriosis resection using near-infrared fluorescence imaging with indocyanine green: a prospective case series and review of literature. J Robot Surg 2020;14:145-54.

18. Nezhat C, Lewis M, Kotikela S, Veeraswamy A, Saadat L, Hajhos- seini B, et al. Robotic versus standard laparoscopy for the treatment of endometriosis. Fertil Steril 2010;94:2758-60.

19. Chu CM, Chang-Jackson SC, Nezhat FR. Retrospective study assessing laparoscopic versus robotic assisted laparoscopic treatment of severe endometriosis. J Minim Invasive Gynecol 2011;18:S101.

20. Dulemba JF, Pelzel C, Hubert HB. Retrospective analysis of robotassisted versus standard laparoscopy in the treatment of pelvic pain indicative of endometriosis. J Robot Surg 2013;7:163-9.

21. Nezhat FR, Sirota I. Perioperative outcomes of robotic assisted laparoscopic surgery versus conventional laparoscopy surgery for advanced-stage endometriosis. JSLS 2014;18:e2014.00094.

22. Nezhat CR, Stevens A, Balassiano E, Soliemannjad R. Roboticassisted laparoscopy vs conventional laparoscopy for the treatment of advanced stage endometriosis. J Minim Invasive Gynecol 2015;22:40-4.

23. Magrina JF, Espada M, Kho RM, Cetta R, Chang YH, Magtibay PM. Surgical excision of advanced endometriosis: perioperative outcomes and impacting factors. J Minim Invasive Gynecol 2015;22:944-50.

24. Soto E, Luu TH, Liu X, Magrina JF, Wasson MN, Einarsson JI, et al. Laparoscopy vs. Robotic Surgery for Endometriosis (LAROSE): a multicenter, randomized, controlled trial. Fertil Steril 2017;107:996-1002.e3.

25. Chen SH, Li ZA, Du XP. Robot-assisted versus conventional laparoscopic surgery in the treatment of advanced stage endometriosis: a meta-analysis. Clin Exp Obstet Gynecol 2016;43:422-6.

26. Haueter R, Schütz T, Raptis DA, Clavien PA, Zuber M. Metaanalysis of single-port versus conventional laparoscopic cholecystectomy comparing body image and cosmesis. Br J Surg 2017;104:1141-59.

27. Fagotti A, Bottoni C, Vizzielli G, Gueli Alletti S, Scambia G, Marana E, et al. Postoperative pain after conventional laparoscopy and laparoendoscopic single site surgery (LESS) for benign adnexal disease: a randomized trial. Fertil Steril 2011;96:255-9.e2.

28. Demirayak G, Özdemir İA, Comba C, Aslan Çetin B, Aydogan Mathyk B, et al. Comparison of laparoendoscopic single-site (LESS) surgery and conventional multiport laparoscopic (CMPL) surgery for hysterectomy: long-term outcomes of abdominal incisional scar. J Obstet Gynaecol 2020;40:217-21.

29. Bucher P, Pugin F, Ostermann S, Ris F, Chilcott M, Morel P. Population perception of surgical safety and body image trauma: a plea for scarless surgery? Surg Endosc 2011;25:408-15.

30. Moon HS, Shim JE, Lee SR, Jeong K. The comparison of robotic single-site surgery to single-port laparoendoscopic surgery for the treatment of advanced-stage endometriosis. J Laparoendosc Adv Surg Tech A 2018;28:1483-8.

31. Dobbs RW, Halgrimson WR, Madueke I, Vigneswaran HT, Wilson JO, Crivellaro S. Single-port robot-assisted laparoscopic radical prostatectomy: initial experience and technique with the da Vinci® SP platform. BJU Int 2019;124:1022-7. 
32. Kaouk J, Valero R, Sawczyn G, Garisto J. Extraperitoneal singleport robot-assisted radical prostatectomy: initial experience and description of technique. BJU Int 2020;125:182-9.

33. Bellelis P, Dias JA Jr, Podgaec S, Gonzales M, Baracat EC, Abrão MS. Epidemiological and clinical aspects of pelvic endometriosis-a case series. Rev Assoc Med Bras (1992) 2010;56:467-71.

34. Fauconnier A, Chapron C. Endometriosis and pelvic pain: epidemiological evidence of the relationship and implications. Hum Reprod Update 2005;11:595-606.

35. Di Maida F, Mari A, Morselli S, Campi R, Sforza S, Cocci A, et al. Robotic treatment for urinary tract endometriosis: preliminary results and surgical details in a high-volume single-institutional cohort study. Surg Endosc 2020;34:3236-42.

36. Garry R, Clayton R, Hawe J. The effect of endometriosis and its radical laparoscopic excision on quality of life indicators. BJOG 2000;107:44-54.

37. Redwine DB, Wright JT. Laparoscopic treatment of complete obliteration of the cul-de-sac associated with endometriosis: longterm follow-up of en bloc resection. Fertil Steril 2001;76:358-65.

38. Ruffo G, Sartori A, Crippa S, Partelli S, Barugola G, Manzoni A, et al. Laparoscopic rectal resection for severe endometriosis of the mid and low rectum: technique and operative results. Surg Endosc 2012;26:1035-40.

39. Donnez $\mathrm{O}$, Roman $\mathrm{H}$. Choosing the right surgical technique for deep endometriosis: shaving, disc excision, or bowel resection? Fertil Steril 2017;108:931-42.

40. Nezhat C, Hajhosseini B, King LP. Robotic-assisted laparoscopic treatment of bowel, bladder, and ureteral endometriosis. JSLS 2011;15:387-92.

41. Lim PC, Kang E, Park do H. Robot-assisted total intracorporeal low anterior resection with primary anastomosis and radical dissection for treatment of stage IV endometriosis with bowel involvement: morbidity and its outcome. J Robot Surg 2011;5:273-8.

42. Ercoli A, D'Asta M, Fagotti A, Fanfani F, Romano F, Baldazzi G, et al. Robotic treatment of colorectal endometriosis: technique, feasibility and short-term results. Hum Reprod 2012;27:722-6.

43. Collinet P, Leguevaque P, Neme RM, Cela V, Barton-Smith P, Hébert T, et al. Robot-assisted laparoscopy for deep infiltrating endometriosis: international multicentric retrospective study. Surg Endosc 2014;28:2474-9.

44. Neme RM, Schraibman V, Okazaki S, Maccapani G, Chen WJ, Domit CD, et al. Deep infiltrating colorectal endometriosis treated with robotic-assisted rectosigmoidectomy. JSLS 2013;17:227-34.

45. Vitobello D, Fattizzi N, Santoro G, Rosati R, Baldazzi G, Bulletti C, et al. Robotic surgery and standard laparoscopy: a surgical hybrid technique for use in colorectal endometriosis. J Obstet Gynaecol Res 2013;39:217-22.

46. Siesto G, leda N, Rosati R, Vitobello D. Robotic surgery for deep endometriosis: a paradigm shift. Int J Med Robot 2014;10:140-6.

47. Pellegrino A, Damiani GR, Trio C, Faccioli P, Croce P, Tagliabue F, et al. Robotic shaving technique in 25 patients affected by deep infil- trating endometriosis of the rectovaginal space. J Minim Invasive Gynecol 2015;22:1287-92.

48. Abo C, Roman H, Bridoux V, Huet E, Tuech JJ, Resch B, et al. Management of deep infiltrating endometriosis by laparoscopic route with robotic assistance: 3-year experience. J Gynecol Obstet Hum Reprod 2017;46:9-18.

49. Morelli L, Perutelli A, Palmeri M, Guadagni S, Mariniello MD, Di Franco G, et al. Robot-assisted surgery for the radical treatment of deep infiltrating endometriosis with colorectal involvement: shortand mid-term surgical and functional outcomes. Int J Colorectal Dis 2016;31:643-52.

50. Graham A, Chen S, Skancke M, Moawad G, Obias V. A review of deep infiltrative colorectal endometriosis treated robotically at a single institution. Int J Med Robot 2019;15:e2001.

51. Comiter CV. Endometriosis of the urinary tract. Urol Clin North Am 2002;29:625-35.

52. le Carpentier M, Merlot B, Bot Robin V, Rubod C, Collinet P. Partial cystectomy for bladder endometriosis: robotic assisted laparoscopy versus standard laparoscopy. Gynecol Obstet Fertil 2016;44:315-21.

53. Bot-Robin V, Rubod C, Zini L, Collinet P. Early evaluation of the feasibility of robot-assisted laparoscopy in the surgical treatment of deep infiltrating endometriosis. Gynecol Obstet Fertil 2011;39:407-11.

54. Frick AC, Barakat EE, Stein RJ, Mora M, Falcone T. Robotic-assisted laparoscopic management of ureteral endometriosis. JSLS 2011:15:396-9.

55. Brudie LA, Gaia G, Ahmad S, Finkler NJ, Bigsby GE 4th, Ghurani $\mathrm{GB}$, et al. Peri-operative outcomes of patients with stage IV endometriosis undergoing robotic-assisted laparoscopic surgery. J Robot Surg 2012;6:317-22.

56. Giannini A, Pisaneschi S, Malacarne E, Cela V, Melfi F, Perutelli A, et al. Robotic approach to ureteral endometriosis: surgical features and perioperative outcomes. Front Surg 2018;5:51.

57. Liu H, Kinoshita T, Tonouchi A, Kaito A, Tokunaga M. What are the reasons for a longer operation time in robotic gastrectomy than in laparoscopic gastrectomy for stomach cancer? Surg Endosc 2019;33:192-8

58. Wottawa CR, Genovese B, Nowroozi BN, Hart SD, Bisley JW, Grundfest WS, et al. Evaluating tactile feedback in robotic surgery for potential clinical application using an animal model. Surg Endosc 2016;30:3198-209.

59. Dousset B, Leconte M, Borghese B, Millischer AE, Roseau G, Arkwright S, et al. Complete surgery for low rectal endometriosis: long-term results of a 100-case prospective study. Ann Surg 2010;251:887-95.

60. Knabben L, Imboden S, Fellmann B, Nirgianakis K, Kuhn A, Mueller MD. Urinary tract endometriosis in patients with deep infiltrating endometriosis: prevalence, symptoms, management, and proposal for a new clinical classification. Fertil Steril 2015;103:147-52.

61. Luca F, Valvo M, Ghezzi TL, Zuccaro M, Cenciarelli S, Trovato C, et 
Robot surgery for endometriosis | Kang JH, et al.

al. Impact of robotic surgery on sexual and urinary functions after fully robotic nerve-sparing total mesorectal excision for rectal cancer. Ann Surg 2013;257:672-8.

62. Ceccaroni M, Pontrelli G, Scioscia M, Ruffo G, Bruni F, Minelli L. Nerve-sparing laparoscopic radical excision of deep endometriosis with rectal and parametrial resection. J Minim Invasive Gynecol 2010;17:14-5.

63. Kirchhoff P, Clavien PA, Hahnloser D. Complications in colorectal surgery: risk factors and preventive strategies. Patient Saf Surg 2010;4:5
64. Sendag F, Zeybek B, Akdemir A, Ozgurel B, Oztekin K. Analysis of the learning curve for robotic hysterectomy for benign gynaecological disease. Int J Med Robot 2014;10:275-9.

65. Tang FH, Tsai EM. Learning curve analysis of different stages of robotic-assisted laparoscopic hysterectomy. Biomed Res Int 2017;2017:1827913.

66. Leijte E, de Blaauw I, Van Workum F, Rosman C, Botden S. Robot assisted versus laparoscopic suturing learning curve in a simulated setting. Surg Endosc 2020;34:3679-89. 